"Are Institutionalists an Endangered Species?"

by

D avid Colander

February, 2003

MIDDLEBURY COLLEGE ECONOMICS DISCUSSION PAPER NO. 03-03

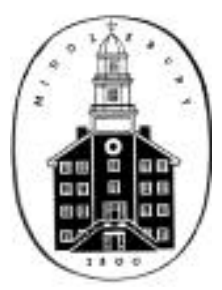

DEPARTMENT OF ECONOMICS

MIDDLEBURY COLLEGE

MIDDLEBURY, VERMO NT 05753

http:/ / www.middlebury.edu/ econ 


\section{Are Institutionalists an Endangered Species?}

David Colander

It has been fifty years since David Hamilton published his provocative book, Newtonian Classicism and Darwinian Institutionalism. A revised edition of this book was published as Evolutionary Economics: A Study of Change in Economic Thought in 1970, and a Transactions edition of the book was published in 1991 and again in 1999. Clearly it is a book with staying power. One of the reasons for that staying power is that it provides a foundation for institutional thought-a reason for the Association for Evolutionary Economics to exist. It does so by distinguishing Institutionalists from standard economists. [In this paper I distinguish Institutionalists (with a capital $I$ ), by which I mean the Institutionalists within AFFE who maintain direct ties to old Institutionalists, from quasi- and neo- institutionalists (with a small $i$ ) who spend far less time emphasizing those ties and whose work is considered part of modern mainstream economics.]

Hamilton's book includes the following arguments:

- A distinct group of institutionalist economic work exists. This work has a sufficiently different methodology to deserve to be called institutionalist economics and differentiated from standard economics.

- Institutionalism represents a revolutionary way of observing economic phenomena that is not complementary to classical economics.

- Standard economics is too pessimistic. Its overall policy message is "that if something must be done about economic conditions do the least possible and be cautious about that" (Hamilton 1999, vii). Institutionalist economics offers a much more optimistic view of policy.

- Standard economics follows a mechanistic Newtonian point of view, whereas institutionalist economics follows a "process tools" approach, which captures the evolution reality of economic change. 
- The difference between institutionalist economics and standard economics can be found in their concepts of change.

- Institutionalist economists are more capable of coming to grips with the major economic issues.

Although the book was written fifty years ago, Hamilton wrote in the introduction to the 1991 edition that the arguments were still relevant. Even now, in the twenty-first century, they remain relevant. We can see that relevance by considering the central elements of Institutionalism today as put forward by Anne Mayhew (2002) as an approach that economists who want a meaningful economics should follow. Mayhew argued that institutional economics is a "reasonably coherent, pluralistic and non-autistic approach to the study of economies and economic issues" with the following four basic themes:

1. Regularities in the organization of both production and distribution are the same as all other social regularities in that they are human creations and are subject to change by human intervention. In other words, there is no "natural economy," and there is no reason to assume that an idealized market system is historically or morally superior to other social systems.

2. It follows from the previous theme that as humans create their economies, they can change those economies to solve perceived problems. A central part of economic analysis should therefore be the identification of problems-patterns of production and distribution that are not in accord with the goals of society. This analysis should lead to reasoned advocacy of reform through normal political and social processes.

3. While Institutional economists see their role as one of criticism and advocacy, they do not purport to offer permanent solutions or design of utopias.

4. In order to understand the processes of ongoing change, and in order to understand the human organization of production and distribution, a variety of tools are useful, including statistical analysis, observation, and the study of history. In all of the institutionalist work, the tools are just that: ways to achieve the goal of understanding 
the patterns of human behavior and how they change. The tools do not define the discipline.

These themes blend nicely with Hamilton's and characterize my understanding of institutional economics. Since this symposium is meant to discuss the distinguishing features of the Association for Evolutionary Economics and the Journal of Economic Issues, in this article I consider the general issues raised by Hamilton and Mayhew from the perspective of a standard economist who is sympathetic to institutionalist ideas but who would not be classified as an institutionalist in the sense that Hamilton and Mayhew meant. Specifically, I will address two of the same questions that Hamilton addressed:

- Is there a differentiable group of institutionalists, and, if so, what distinguishes them?

- Should there be a distinguishable group of institutionalists, and if so, what should distinguish them?

In discussion of these questions I shall outline some choices that I believe institutional economists face today and what I see as the likely outcomes of the various choices.

\section{Is There a Differentiable Group of institutionalists, and, If There Is, What Distinguishes Them?}

My answer to the first part of this question is the same as Hamilton's and Mayhew's: there is a differentiable group of economists that goes under the name institutionalist. However, I do not believe that, today, differences between institutionalists and standard economics can be found in their concepts of change and, more generally, in differences in content. The reason why one cannot differentiate institutional economics from standard economics on content is that a narrow "standard economics" in terms of content in the sense that Hamilton had in mind has evolved into a field of inquiry with a much broader and eclectic focus.

Hamilton's initial title summed up his view of the different contents: standard economics was mechanistic; institutional economics was evolutionary. While that may have been the case when Hamilton initially wrote his book, I do not believe it to be the case now. Indeed, one of the key themes of my recent writing has been that neoclassical economics is dead and that the term is 
no longer helpful as a descriptor of modern economics (Colander 2000). Its death has not been noticed because it died a slow, lingering death; it simply faded away.

One of the reasons for the death of neoclassical economics is developments in mathematics and computational technology that have made it possible to deal with dynamic issues, including non-linear dynamic complex systems that previously were outside the purview of formal mathematics. As Hamilton rightly pointed out when he first wrote, the mathematical nature of classical economics played a big role in its inability to formally study change. Since classical economists wanted to keep their analysis formal, the mathematical constraints forced them to avoid complicated issues of change. Thus, for example, Alfred Marshall avoided including general equilibrium issues in his policy discussions because they were beyond formal analysis. (See Colander 2000.)

Mathematics has evolved over time, and today, with the developments in non-linear dynamics and computer simulations that give insight into iterative and cumulative processes, we are in a better position to study change formally. Thus where Joseph Schumpeter (1954) could say that a unique equilibrium was necessary for a science to exist, today few economists would see it as necessary, and the study of equilibrium selection mechanisms is considered an important branch of study within standard economics. Work on complexity has shown how organization can spring spontaneously out of chaos and has led to the development of a new econophysics branch of economics building on insights of statistical mechanics. (See Arthur, Durlauf, and Lane 1997.) Similarly, developments in evolutionary game theory have provided an alternative mechanism to formally study the evolution of systems, and experimental work has allowed behavioral economists to explore and test other assumptions rather than simply accept the rather sterile rationality that characterized neoclassical economics.

The reality is that today standard economics includes significant discussion of evolutionfor example, evolutionary game theory and simulations. Similarly, modern mainstream economics has shown an enormous interest in institutions. New institutionalists abound, and major research programs on the role of institutions in the economy thrive within mainstream economics. To capture this interest, in our history of thought text (Landreth and Colander 2002) 
we distinguish Institutionalists from quasi- and neo- institutionalists who spend far less time emphasizing those ties and whose work is considered part of modern mainstream economics. It is because standard economics has evolved in the twenty-first century that one can no longer differentiate Institutionalist economics from standard economics on the basis of what issues are considered legitimate for study. ${ }^{1}$ Both consider change and evolution.

I suspect that the above argument will be disputed by many Institutionalists, who will cite the content of textbooks, not the research interests of cutting-edge economists, as support for their position. In response to that argument, I agree that these changes in standard economics are difficult to see in undergraduate texts, which lag the profession often by decades. Most of the criticisms that Hamilton made of "neoclassical economics" can still be made of the economics taught in most current principles textbooks. But the argument--that because these new developments do not show up as part of the principles and intermediate books they are not part of the core of modern standard economics--is unconvincing to me.

In my view what is included in what we teach is an issue of pedagogy, not of what is necessarily believed. That view seems to have been the view of Marshall, who in his Principles of Economics stated that although economics belonged in the domain of biology, the focus of his book was going to be much more on mechanical processes and concepts. The reason was that the simplicity of those mechanical models made them easier for students to understand. Good modern economists make that same argument; they see the mechanical and static tools we teach undergraduates as useful teaching tools to introduce students to ideas whose more complicated expression would push students beyond their analytic limits. ${ }^{2}$ I agree with that argument to some degree; teaching a mechanistic model can be useful as long as it is emphasized to students that the domain of economics lies in biology, not mechanics, and some focus is given to more complex ideas.

To make clear what I mean by the term neoclassical economics, let me list what I see as its distinguishing elements. These include a focus of analysis on allocation of resources at a given moment in time; a required acceptance of some variation of utilitarianism as playing a central role in understanding the economy; a focus on marginal tradeoffs; an acceptance of far-sighted 
rationality; and an insistence on methodological individualism. When Hamilton first wrote his book, if one did not accept those elements one was considered a heterodox economist. Thus, institutionalists were excluded from standard economics based on the content of their arguments, such as their belief that an individual's wants were shaped by culture and thus could not be considered separate from that culture. At that time it was reasonable to distinguish institutionalists from standard economists on the basis of their concepts of change, as Hamilton did.

Today, standard economics is no longer defined by content. Adhering to the above elements is no longer required for someone to be in the mainstream of economics. (See Colander 2000 for a full discussion.) Let me be clear: my argument is not that many economists do not continue to use these elements nor that some economists do not claim that some of these elements should be central to economic analysis; my argument is that standard economics does not require adherence to these five attributes. It is much more eclectic. For example, the interest in allocation of resources at a given moment in time ended long ago, the problems solved. The focus of research quickly turned to allocation over time. In the 1990s, for example, growth has been a key topic. New growth theory is decidedly mainstream and decidedly non-neoclassical. In fact, it is generally contrasted with neoclassical growth theory.

Modern economics is very much concerned with evolution. For example, Avinash Dixit $(1991,225)$ argued that we need an "evolutionary perspective" and that it must "take history and the institutions of politics seriously." More and more economists are considering culture in their analysis. This can be in the sense of social capital (see Puttman 2000) or invisible institutions discussed by Kenneth Arrow (1974).

We see something similar with utilitarianism and marginalism. Few standard economists today accept utilitarianism, and almost all agree that one must go beyond marginalist analysis. While many undergraduate texts still present economics within a marginal framework, that is not the way it is presented in graduate schools, nor is it the way top modern mainstream economists think about issues. In fact, by the 1930s, in cutting-edge theory, calculus was already being dropped, having been mined for its insights, and math was moving to set theory and topology as 
economists tried to expand the domain of economics to include a wider variety of topics. In modern graduate microeconomics, game theory has almost completely replaced calculus as the central modeling apparatus. Similar arguments can be made for the other distinguishing elements of neoclassical economics.

Consider the following economists: David Romer, Buz Brock, John Thaler, William Baumol, George Akerlof, Joe Stiglitz, David Card, Alan Krueger, Paul Krugman, Ken Arrow, Amartya Sen, Thomas Shelling. Each is considered a top modern economist, but each operates outside the "neoclassical framework" in portions of his work.

If content is not the distinguishing feature of modern institutionalist economics, what is? My answer is method. While modern economics is open in terms of content, it is not open in terms of method. Modern economics requires students entering into economics to focus on technical modeling and to go through a graduate program that prepares them to use that method in their analysis. As Robert Solow (1997) spelled out and as Jurg Niehans (1990) emphasized, the modeling approach to problems is the central element of modern economics. Modeling is not presented as an end in itself (although all too often it is), but (at least among the economists I hang around with) there is a continual discussion of the need to empirically test. The argument is that the formal modeling is undertaken to make the models empirically testable and applicable to policy, with formal statistical techniques. 3 Models that are considered acceptable are still more likely to be methodologically individualistic than not, but if a researcher can make a convincing argument that his or her model provides insight and fits the empirical evidence, a wide range of models are acceptable. For example, we can see work on agent-based models with evolving decision rules and statistical mechanics models in which the only meaningful concept of equilibrium is on the aggregate level.

Institutionalists (capital $I$ ) may follow a variety of methods, but in the publications in the Journal of Economic Issues they concentrate on studies using a different methodology from that generally found within standard economics. If one were to judge their method from articles published in the Journal of Economic Issues, one would conclude that while, in principle, institutionalist economics has a very open methodology (as Mayhew stated, the tools do not 
define the discipline), in practice, it is not so clear. The methods I see at institutionalist sessions at the American Economic Association meetings, and which describe the typical article in the Journal of Economic Issues, are primarily verbal, non-mathematical methods: literary exegesis, verbal argumentation, and reasoned thought, with empirical data presented simply in table form rather than in complicated econometrics.

I am not disparaging this institutionalist method; I happen to like it and find it very illuminating (I also find the economics profession's unwillingness to allow that method confining and inappropriate and have chided its members about it in a number of articles.) But the reality is, in practice, articles in the Journal of Economic Issues follow a different method from articles in a standard economics journal. So not only do institutionalist economics articles differ in content; they also differ by method. Looking at the articles in the Journal of Economic Issues over the last ten years, I saw few econometric studies or technical articles using, say statistical mechanics, to study aggregate equilibrium. Institutionalists may be using those other methods, but they do not publish articles using them in the Journal of Economic Issues.

My point is that while, in principle, Institutionalists are committed to an open methodology, in practice they tend to follow a verbal, case study, historical approach, which places little direct reliance on formal econometric studies or mathematical theory. This places them in sharp contrast to standard economics, where almost all the arguments about the role of institutions are in mathematical form or empirical in some sense. If you are looking for the latest work on agent-based models of institutions, simulations, evolutionary game theoretical models of institutions, or large statistical studies looking for fits of institutions to general complexity laws such as Zipf's law, all of which have been used by economists to study the role of institutions and of the evolution of the economy, you would turn to, say, the Journal of Behavioral Economics, not the Journal of Economic Issues. The reality is that when economists with institutional leanings are writing papers using these methods they do not think of the Journal of Economic Issues as an outlet.

Now there are a number of justifiable reasons for the Journal of Economic Issues to focus on historical case studies and verbal argumentation. For example, one could make a strong 
argument that it is necessary to offset standard economics' over-focus on mathematical methods with a counterbalancing over-focus on nonmathematical methods. But regardless of the reason, the reality is that, despite being open to various methodologies, Institutional economics is associated with a verbal methodology and does not foster active research using other methodologies.

The verbal methodological focus is self-reinforcing. Individuals trained by Institutionalist economists are generally trained by individuals who focus on verbal analysis, and they teach their students that same analysis. Advancement in Institutionalist-oriented institutions depends on publication in journals that focus on verbal analysis, and that analysis becomes more deeply built into the methodology. Advancement in non-Institutionalist institutions gives little weight to these publications. 4 The end result is a subgroup of Institutionalist scholars whose primary approach to problems is verbal analysis. 5

\section{Should There Be a Distinguishable Group of Institutionalists, and, If So, What Should Distinguish Them?}

Let me now turn to my second set of questions: Should there be a distinguishable group of Institutionalists, and, if so, what should distinguish them? On these questions I am far more eclectic. In some ways, my view is that in terms of content-if by content one means a recognition by modern economists that evolution and institutions are fundamentally important to studying the economy-Institutionalists have won. Standard economics today is much more open to the study of change and institutions than it was fifty years ago. True, there are still many laggards, and much of economic analysis still reflects the old style neoclassical approach. But the cuttingedge work is open to change and indeed understands that it needs to change. However, while the future of standard economics involves a study of change and a study of institutions, that future also involves highly complex analysis that will be centered around mathematics and non-verbal analysis, which leaves Institutionalists out of standard economics. It is primarily because of method, not content, that Institutionalists are seen as outside standard economics today.

Faced with this situation, Institutionalists have a number of options in regard to distinguishing themselves: 
1. Continuing to emphasize the difference in content with standard economics, contrasting institutionalism with that part of standard economics that emphasizes neoclassical principles. Being separate but equal. (Be separate, but equal.)

2. Incorporating more of the modern economics methods into their approach and hence into their journal, exploring the role of institutions and change in a more technical manner using more mathematical methods. (Declare victory and assimilate.)

3. Downplaying the difference in content by emphasizing their connection with the more technical methods of exploring change, while still maintaining their primarily verbal methodology. (Differentiate only on method.)

Each has its own advantages and problems, and the approaches are not necessarily exclusive.

\section{Continuing to Emphasize the Difference in Content}

The argument I made about the content of standard economics and Institutional economics is debatable. It is based upon a definition of standard economics that interprets its content as broadly as possible. Using a narrower definition of standard economics, and interpreting its content narrowly, would allow one to continue to emphasize differences in content. Doing so would allow Institutional economics to continue much as it has. The advantage of that approach is that it involves the least change; the problem with that approach is that it involves the least change; it leaves Institutional economics as a group quite separate from standard economics. If this is the path followed, the focus of Institutional economics will remain at a small group of schools that have chosen that path, and its influence in the economics profession will likely remain small. It will lead to more and more Institutionalists being squeezed from standard graduate programs into history departments or otherwise being separated from the core of the profession.

Institutionally, I see this position as eventually leading to the extinction of Institutionalists within the economics profession. Rightly or wrongly, there is an enormous pressure for standardization of content. Deans feel it; department chairs feel it; and that pressure leads toward a standardized approach to teaching economics. Pockets of resistance can exist, and 
even temporarily prosper, but eventually through the normal hiring and retirement process, most schools will succumb. Institutionalist graduate schools will succumb first, as many already have, but then, since graduate schools provide the future teachers, undergraduate schools will eventually follow. It is possible that Institutionalist economics could regroup outside the structure of economics departments, perhaps in history of public policy departments. Within economics departments, however, I see Institutionalists' future as highly limited if they follow this approach.

I am not arguing that this is necessarily a bad strategy. In evolutionary systems things change, and perhaps the essence of the Institutionalist approach can be maintained outside of the profession as it is currently constituted. ${ }^{6}$ If this method is followed, I see it as likely that it will directly take on mainstream economics' method, which will direct it into a more philosophical journal such as the Journal of Economic Methodology. Thus, I see special issues looking at the empirical criticisms of economics and a section of the journal devoted to criticisms of the empirical work that is done.

\section{Incorporating More Formalistic Methods into the Institutional Approach}

An alternative strategy would be to minimize the differences in approach and simply incorporate much of (small $i$ ) institutionalist work currently being done. This strategy would involve taking a loose definition of standard economics and essentially blending into that part of the profession that is emphasizing change and institutions. It would involve removing the capital I from Institutionalists. Essentially, this is a declare-victory-in content-and-assimilate strategy.

The advantage of doing this would be that it would involve a marriage that would be likely to play a central role in defining the future direction of economics. The disadvantage is that it would involve developing a whole new set of skills for Institutionalists that are inconsistent with its recent past (although in the beginning of Institutional economics, economists such as Wesley Claire Mitchell were at the cutting edge of statistical work). It would depreciate the human capital of many current Institutionalists and would mean giving up AFEE's identity. Whether it is worthwhile to do that in order to have some influence on the future direction of the profession is a question that Institutionalists must decide. 
Downplaying the Difference in Content While Still Maintaining a Primarily Verbal Methodology

A third strategy would be for Institutionalists to embrace the mathematical methods as legitimate but to focus on discussing their relevance and relating the methods for policy, especially in the Journal of Economic Issues. An example of the type of paper that would be more typical if this approach were followed is Staveren 1999. The advantage of this strategy, as compared with the previous one, is that it builds on the methodological strength of Institutional Economics while at the same time recognizing the changes in the profession. If this strategy is followed I see the Journal of Economic Issues being more like the Journal of Economic Perspectives, which focuses on modern work on institutions and evolution.

The disadvantage of this approach is that Institutionalists are likely to continue to be minimized within standard economics even if they follow this role and would be unlikely to make significant inroads into departments. I think this is sad, but true. In my ideal world, if they followed this route, I would see Institutional Economics as one of the subfields of graduate schools, with an emphasis on verbal analysis and exposition that would prepare students for teaching and policy, areas that are not currently covered. It would build upon the technical work, exploring its limitations, but it would not create new technical work.

In my view there is an enormous need for some group of economists to play this role, but I have no illusions about its possibilities for success. Standard economics is committed to its technical analysis and continues to downplay any alternative way of considering issues. Undergraduate teaching is not seen as a legitimate goal of most top graduate programs, and they are unlikely to hire anyone to teach it. Preparation for it would have to come from Institutionalistoriented programs that would add more technical elements to their curriculum to provide an appropriate basis for students to see what they are studying. Students would be taught more about technical programs but would not be required to extend the frontiers of the theory-simply to apply the theory to policy and to translate the theory into stories that students could understand. 
My own view is that in order to follow this approach Institutionalist economics would have to be agnostic about policy and perhaps integrate with the Austrian economics program, which provides a different ideological view but which also shares some of the same views about institutions and change as central to the study of economics that Institutionalists hold.

\section{Conclusion}

Regardless of what option Institutionalists follow, their continued existence in the short run is assured. One reason for that is the Journal of Economic Issues. It is a journal that is widely held by libraries and one that can further the program of Institutionalists. It got in on the ground floor and provides an outlet for institutionally oriented economists to publish. In doing so it provides them a way of progressing in the field and gives a voice to Institutional economists. It is an organization's journal that gives the organization its lifeblood. Thus, the editorial decisions that it makes will play a key role in the future.

Nonetheless, because of the evolution of the profession, in the long run Institutional economists are an endangered species. They drew their lifeblood criticizing neoclassical economics, and with the death of neoclassical economics, they must search elsewhere for sustenance.7 With a well-defined neoclassical economics, Institutionalists could go on to set up their content in juxtaposition to the standard approach. Without it, that is no longer possible, and to ensure their future existence, Institutionalists will have to deal with the new situation.

\section{Notes}

1. The movement toward an analysis of institutions by mainstream economics has previously been noted by Mark Tool (1981) and Douglas Kinnear (2002).

2. In my discussion of "good modern economists," I mean economists who are aware of the latest developments in economics and who do not have a strong ideological agenda. I fully agree that there are economists who are not enlightened and that they can be teaching what they teach for different reasons from those that I give here. I think modern economists and Institutionalists will be in agreement on the problems with that economic pedagogy. The issue is not whether one agrees or disagrees with this pedagogical view of 
the necessity of simplification; the issue is that for good modern economists it is a pedagogical reason underlying why the contents of texts and the content of research can differ.

3. I have my disagreements with how well economists succeed in this (see Colander 1990). But that is what they say they are attempting.

4. This is a description of reality, not the way I think things should be. In my view, there is far too much focus on method and where ideas are published and not on what the ideas are. Advancement committees seem unwilling to make decisions about quality of ideas.

5. Again, I emphasize: this is not necessarily bad; I am simply describing what I see the reality to be.

6. As Institutional economists know in an evolutionary setting, the rise and fall of disciplines and fields is to be expected. Given the direction it is following, in fifty years it is highly unlikely that the concept "economics profession" will have much meaning. See Colander 2000.

7. The issues for Institutionalists are similar to those of other heterodox economists because the term "neoclassical economics" was most used by heterodox economists to describe what they were against-what they objected to. I can always tell when I'm in a heterodox meeting; the conversation is scattered with references to neoclassical economics, usually specified in rather negative terms, such as Newtonian or mechanical. Similarly, I can always tell when I am at a mainstream meeting, because I don't hear the term neoclassical at all.

\section{References}

Arrow, Kenneth. The Limits of Organization. New York: Norton, 1974.

Arthur, W. B., Steven Durlauf and David Lane (eds). The Economy as an Evolving Complex System. Reading MA: Addison Wesley, 1997. 
Colander, David. Why Aren’t Economists More Important than Garbagemen?. New York: Sharpe Publishing, 1991.

-—-. “The Death of Neoclassical Economics.” Journal of the History of Economic Thought 22, no. 2 (June 2000): 127-144.

--_. "Marshallian General Equilibrium." Eastern Economic Journal 21, no. 3 (1995): 281-294.

-—-. “New Millennium Economics: How Did It Get This Way, and What Way Is It?” Journal of Economic Perspectives 14, no. 1 (winter 2000): 121-132.

Dixit, Avinash K. and Berry J. Nalebuff. Thinking Strategically: The Competitive Edge in Business, Politics, and Everyday Life. New York and London: Norton, 1991.

Hamilton, David. Evolutionary Economics: A Study of Change in Economic Thought. New Jersey: Transaction Publishers, 1999.

Kinnear, Douglas. “The 'Compulsive Shift' to institutional Concerns in Recent Labor Economics.” Journal of Economic Issues 33, no.1 (March 1999) 169-182.

Landreth, Harry and David Colander. History of Economic Thought 4th Ed. Massachusetts: Houghton Mifflin \& Co., 2002.

Mayhew, Anne. “Some Old But Good Ideas.” Post Autistic Newsletter, 2002.

Niehans, Jurg. A History of Economic Theory. Maryland: Johns Hopkins University Press, 1990.

Putman, Robert. Bowling Alone. New York: Simon and Schuster, 2000.

Schumpeter, Joseph. History of Economic Analysis. New York: Oxford University Press, 1954.

Solow, Robert. "How Did Economics Get That Way and What Way Did It Get?” Daedalus 126, no.1 (winter 1997): 39-59.

Staveren, Irene van. “Chaos Theory and institutional Economics: Metaphor or Model?” Journal of Economic Issues 33, no. 1 (March 1999): 141-168.

Tool, Mark. “The Compulsive Shift to institutional Analysis.” Journal of Economic Issues 15, no.3 (September 1981): 569-592. 